\title{
Estimating global solar radiation using a hybrid parametric model from MODIS data over the Tibetan Plateau
}

\author{
Hailong Zhang ${ }^{\mathrm{a}, \mathrm{b}, \mathrm{c}}$, Xiaozhou Xin ${ }^{\mathrm{a}, *}$, Li Li ${ }^{\mathrm{a}}$, Qinhuo Liu ${ }^{\mathrm{a}}$ \\ ${ }^{a}$ State Key Laboratory of Remote Sensing Science, Jointly Sponsored by the Institute of Remote Sensing and Digital Earth, \\ Chinese Academy of Science, Beijing 100101, China \\ ${ }^{\mathrm{b}}$ State Key Laboratory of Loess and Quaternary Geology, Institute of Earth Environment, Chinese Academy of Science, Xi'an 710061, China \\ ${ }^{c}$ State Key Laboratory of Resources and Environmental Information System, Institute of Geographical Sciences and Natural Resources Research, \\ Chinese Academy of Science, Beijing 100101, China
}

Received 4 June 2014; received in revised form 20 November 2014; accepted 11 December 2014 Available online 7 January 2015

Communicated by: Associate Editor Jan Kleissl

\begin{abstract}
The Tibetan Plateau plays an important role in global atmospheric circulation with its complex terrain. The downward surface shortwave radiation (DSSR) can be obtained from remote sensing data because of its sparse observations and rugged surface. In this paper, a satellite-based scheme is presented to retrieve all-sky downward surface shortwave radiation, which links a look-up table algorithm and satellite images. The look-up table for clear sky and cloudy sky was created separately using a comprehensive 1D physically based radiative transfer model SBDART to achieve a higher computational accuracy and efficiency compared to the comprehensive radiative transfer model. The estimated DSSR was validated using one year pyranometer measurements from 8 stations in the Tibetan Plateau and compared with GEWEX-SRB data with $1^{\circ}$ spatial resolution. The result shows that the largest root mean square error was $60 \mathrm{~W} / \mathrm{m}^{2}$ $(32 \%)$ at Guoluo station, and the least root mean square error was $13 \mathrm{~W} / \mathrm{m}^{2}(13 \%)$ at Golmud station. The bias was larger in summer and smaller in winter, which may be caused by uncertainties in the assumption from the 1D radiative transfer model and MODIS cloud properties product for broken and inhomogeneous clouds. The algorithm we proposed can be applied globally without local calibration because it is independent of climate and the surface elevation.
\end{abstract}

(C) 2014 Elsevier Ltd. All rights reserved.

Keywords: Downward surface shortwave radiation; All-sky irradiance; Look up table; MODIS

\section{Introduction}

Downward Surface Shortwave Radiation (DSSR) is the primary source of energy for the ecosystem and the fundamental energy available at the Earth's surface. DSSR affects energy and carbon dioxide processes between terrestrial ecosystems and the atmosphere and plays an important role in oceanic and atmospheric circulation (Gupta

\footnotetext{
* Corresponding author.

E-mail addresses: zhlnjnu@163.com, zhanghl@radi.ac.cn (H. Zhang), xin_xzh@163.com (X. Xin).
}

et al., 1999; Wild et al., 1995). An accurate estimation of the DSSR is essential for understanding and assessing the radiative forcing of the climate system. However, DSSR observations are relatively scarce in inaccessible areas, such as the Tibetan Plateau (TP) and Polar Regions. Only 122 radiation stations were built in China and are maintained by the China Meteorological Administration (CMA). Most of the stations are located in inhabited areas (Yang et al., 2010). Therefore, DSSR estimation algorithms from remote sensing data or routinely observed atmospheric parameters have been developed. 
In the absence of measurements, DSSR may be estimated using interpolation/extrapolation method from observing DSSR data (Rivington et al., 2006) or Ångström equation based empirical models from meteorological data (Ångström, 1924), such as sunshine hours (Ertekin and Evrendilek, 2007), air temperature (Meza and Varas, 2000 ) and relative humidity (Yang and Koike, 2002). However, these empirical models do not account for radiative extinction processes in the atmosphere, and their coefficients are site-dependent and cannot be used elsewhere without local calibration. These models may work well at local scale for a dense network but have large errors for regional or global scales. Artificial neural network (ANN) methods are also used to develop prediction models to estimate DSSR (Behrang et al., 2010; Qin et al., 2011), but a proper DSSR data set must be employed to train the model. Therefore, this method is not readily applicable to estimate DSSR in high altitude regions because of insufficient observations (Yang et al., 2010).

Because of the limitations of surface data-based radiation models, some attempts have been made to derive DSSR from satellite observations using physical models that incorporate effects from water vapor, cloud absorption, ozone, Rayleigh scattering and aerosols. A number of models have been developed to estimate DSSR distributions on Earth using polar-orbiting or geostationary satellites on horizontal surfaces at various spatial resolutions (Journee and Bertrand, 2010). Three different approaches are available to estimate solar radiation from satellite data: (i) statistical modeling, such as the HELISOAT model for the Meteosat satellite (Rigollier et al., 2004) and the cloud index deriving based model (Perez et al., 2002); (ii) physical modeling using a complicated radiative transfer model (Kim and Liang, 2010); and (iii) parameterized radiative transmittance model (Yang et al., 2006b). Most satellite radiation models can generate daily irradiation with relatively high accuracy compared to ground-based pyranometer data. As reported, $15 \mathrm{~km}$ from the point of interest, hourly satellite estimates are more reliable than pyranometer measurements from ground stations (Houborg et al., 2007). A weakness of geostationary satellites is that they increase in the apparent size of the pixel with the distance from the sub-satellite point, which results in highly questionable solar irradiance maps at high latitudes. However, sun-synchronous polar orbiting satellites, such as the Terra/Aqua aboard the instrument MODerate resolution Imaging Spectroradiometer (MODIS), compromises the spatial-temporal scale of geostationary satellites (i.e., four times per day with a resolution of $1 \mathrm{~km}$ for middle or lower latitude areas). Additionally, the satellite provides detailed atmospheric and land surface properties, which yield the DSSR schemes derived from MODIS (Ryu et al., 2008).

In addition to daily and seasonal cycles, clouds are the largest modulator of solar radiative flux reaching the Earth's surface caused by their spatial and temporal variability. At local scales, topography is a very important driver of solar radiation on the ground. Variability in elevation, azimuth and horizon obstruction results in strong local radiation gradients (Dubayah and Loechel, 1997).

The TP, the highest and largest plateau in the world, located in central Asia with an area of approximately 2.5 million square kilometers and a mean elevation of more than $4000 \mathrm{~m}$, is often regarded as the "Third Pole of the earth" owing to its significant features, such as low temperatures, small air masses and high solar radiation. The TP plays an important role in the Asian monsoon system and exerts a large influence on global atmospheric circulation because of its rugged terrain. Its solar energy resource ranks second in the world next to the Sahara Desert (Zhang et al., 2000). Additionally, underestimations for daily-mean DSSR were found from the Global Energy and Water cycle Experiment-Surface Radiation Budget (GEWEX-SRB) with approximately $-49.2 \mathrm{~W} / \mathrm{m}^{2}$ and $-16.5 \mathrm{~W} / \mathrm{m}^{2}$ for version 2.5 and 2.81 , respectively and the International Satellite Cloud Climatology Project - Flux Data (ISCCP-FD) with approximately $-16.5 \mathrm{~W} / \mathrm{m}^{2}$ at all instrumental sites on the TP. The large errors were caused by neglecting elevation effects (Yang et al., 2008). To further understand the water and energy cycle on the TP, accurate estimations of the surface radiation budget is needed.

This study presents an integrated use of radiative transfer schemes to retrieve all-sky daily DSSR. The cloud optical thickness (COT) and total precipitable water vapor data derived from pairs of MODIS products were used to describe the atmospheric state. This paper is organized as follows: the observed data and MODIS derived atmospheric/land products are briefly described in Section 2. The methodology and issues related to the retrieval of the DSSR are presented in Section 3. Ground measurements and satellite retrievals are compared in Section 4. The conclusions are drawn in Section 5.

\section{Data}

\subsection{Observed data}

The ground-measured daily DSSR data are obtained from pyranometer measurements provided by the National Meteorological Information Center, CMA at 11 ground sites throughout the TP (Table 1). A DFY-4 thermoelectric automatic pyranometer is used to measure daily DSSR and has a spectral response of $0.3-3 \mu \mathrm{m}$, a sensitivity of 7 $14 \mu \mathrm{V} / \mathrm{w} \mathrm{m}^{-2}$, thermal effects of less than $5 \%$ and an annual stability of $5 \%$. All radiometers were calibrated at least once per month at the stations against reference radiometers, and the reference radiometers were calibrated against the regional reference instruments. The regional reference instruments were calibrated every 2 years against the Chinese reference instruments. The calibration process is traceable to the World Radiometric Reference. After 1990, the errors of the pyranometers do not exceed 5\% (Shi et al., 2008). In this study, measured data from January 1, 2007 to December 31, 2007 were used to evaluate the model. 
Table 1

The characteristics of the observations in TP.

\begin{tabular}{|c|c|c|c|c|c|c|c|c|c|c|c|}
\hline Station & Lon. $\left(^{\circ}\right)$ & Lat. $\left(^{\circ}\right)$ & Alt. (km) & $\mathrm{S}\left({ }^{\circ}\right)$ & $\mathrm{A}\left({ }^{\circ}\right)$ & Station & Lon. $\left(^{\circ}\right)$ & Lat. $\left(^{\circ}\right)$ & Alt. (m) & $\mathrm{S}\left({ }^{\circ}\right)$ & $\mathrm{A}\left({ }^{\circ}\right)$ \\
\hline Gangcha & 103.08 & 37.33 & 3.30 & 1.84 & 229 & Yushu & 97.02 & 33.02 & 3.68 & 9.01 & 175 \\
\hline Golmud & 94.90 & 36.42 & 2.81 & 0.23 & - & Guoluo & 100.25 & 34.47 & 3.72 & 0.55 & - \\
\hline Xining & 101.75 & 36.72 & 2.30 & 5.33 & 91 & Changdu & 97.17 & 31.15 & 3.31 & 6.03 & 45 \\
\hline Geer & 80.08 & 32.50 & 4.28 & 1.56 & 152 & Ganzi & 100.00 & 31.62 & 3.39 & 1.04 & 193 \\
\hline $\mathrm{Naqu}$ & 92.07 & 31.48 & 4.51 & 0.81 & - & Hongyuan & 102.55 & 32.80 & 3.49 & 0.27 & - \\
\hline Lhasa & 91.13 & 29.67 & 3.65 & 0.13 & - & & & & & & \\
\hline
\end{tabular}

Lon: longitude; Lat: latitude; Alt: altitude; S: slope; A: aspect $\left(0-360^{\circ}\right.$, measured clockwise from north).

Fig. 1 shows the observation network of DSSR sites over the TP.

Before released by CMA, the daily radiation data over China have already gone through a preliminary qualitycheck. However, this criterion is too simple to meet the application demand (Tang et al., 2010), especially the DSSR model validation. There are some obviously systematic and operational errors for the four stations (Shiquanhe, Naqu, Geer and Lhasa) in Tibet (Shi et al., 2008; Tang et al., 2010). Therefore, the observed data in Naqu, Geer and Lhasa were excluded and the rest 8 stations were used for validation. Furthermore, three procedures of quality check (QC) from Shi et al. (2008) and Tang et al. (2010) were used to assess the data quality of the rest 8 stations and some potentially questionable data were excluded.

QC1: the daily global solar radiation on the surface $(H)$ should not exceed the daily solar radiation at the top of the atmosphere $\left(H_{0}\right)$ and it should exceed the lower limit $\left(0.03 H_{0}\right)$ :

$0.03 H_{0}<H<H_{0}$

QC2: $H$ should not exceed the clear-sky daily radiation $\left(H_{\mathrm{clr}}\right)$ too much:

$H<1.1 H_{\text {clr }}$

QC3: the sunshine duration test from Shi et al. (2008) was used to exclude the data that failed the quality check.
The results of the CMA solar radiation data quality check over the TP were listed in Table 2. There are totally 39 days from the 5 stations (except Yushu, Golmud and Changdu) excluded and the rest of the data were used for the model validation.

\subsection{Satellite data}

The Digital Elevation Model (DEM) from the Shuttle Radar Topography Mission (SRTM) with a 30 arc-sec resolution was re-sampled using the bilinear interpolation method to $1 \mathrm{~km}$ resolution to represent the surface elevation of the Tibet Plateau.

The atmospheric properties were acquired from MODIS Level-2 swath products at a $1 \mathrm{~km}$ resolution comprising the total precipitable water product (MOD/MYD05), the cloud optical thickness and the cloud phase (MOD/ MYD06), and the cloud mask flag (MOD/MYD35) data. Geolocation data were taken from the geo-location product (MOD/MYD03) to rectify the MODIS atmospheric products. The cloud pixels that were flagged as undetermined cloud or data quality flagged as uncertain with $66 \%$ probability were excluded in the DSSR estimation and validation. All MODIS swath data were geo-registered and resampled using the nearest-neighbor interpolation method to $1 \mathrm{~km}$ resolution using MRTSwath Tool. The Terra products (MOD-) were used to determine morning

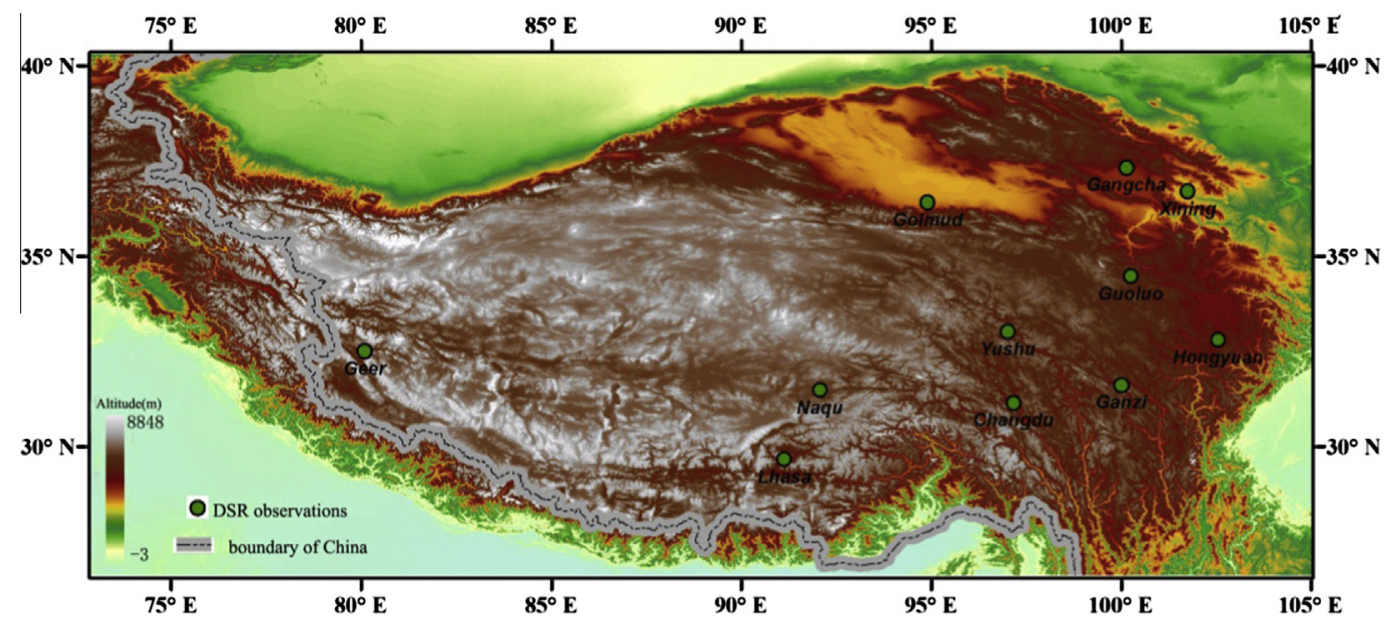

Fig. 1. Locations of the DSSR observations on the Tibetan Plateau. 
Table 2

The result of the CMA solar radiation data quality check over the TP (days).

\begin{tabular}{|c|c|c|c|c|c|c|c|c|}
\hline & Gangcha & Guoluo & Hongyuan & Ganzi & Xining & Yushu & Golmud & Changdu \\
\hline Missing observation & 0 & 5 & 0 & 0 & 2 & 0 & 0 & 0 \\
\hline Failed QC1 & 0 & 0 & 4 & 0 & 4 & 0 & 0 & 0 \\
\hline Failed QC2 & 9 & 8 & 1 & 2 & 0 & 0 & 0 & 0 \\
\hline Failed QC3 & 1 & 3 & 0 & 0 & 0 & 0 & 0 & 0 \\
\hline Excluded & 10 & 16 & 5 & 2 & 6 & 0 & 0 & 0 \\
\hline Valid & 355 & 349 & 360 & 363 & 359 & 365 & 365 & 365 \\
\hline
\end{tabular}

atmospheric conditions, and the Aqua products (MYD-) were used for afternoon atmospheric conditions.

We used China collection 2.0 aerosol optical depth (AOD) dataset as the AOD input. The data was retrieved using the synergetic retrieval of aerosol properties algorithm developed by Xue et al. and the details can be seen in Xue et al., 2014.

The 16-day and 1-km globally tiled Bidirectional Reflectance Distribution Function (BRDF) albedo parameters were acquired from the Terra-Aqua combined product (MCD43B1 V005) to determine the broadband surface albedo at any desired solar zenith angle. The kernel-driven linear BRDF model adopted by MODIS standard products is used in our study. The broadband shortwave albedo $(\alpha(\theta, \lambda))$ was calculated as the interpolation between the white-sky and black-sky albedo values, depending on the AOD, which is calculated as follows:

$\alpha(\theta, \lambda)=\{1-S(\theta, \tau(\lambda))\} \alpha_{\mathrm{bs}}(\theta, \lambda)+S(\theta, \tau(\lambda)) \alpha_{\mathrm{ws}}(\theta, \lambda)$

where $\alpha_{\mathrm{bs}}(\theta, \lambda)$ is the black-sky albedo, $\alpha_{\mathrm{ws}}(\theta, \lambda)$ is the whitesky albedo, $S(\theta, \tau(\lambda))$ is the proportion of diffuse illumination, $\theta$ is the solar zenith angle and $\lambda$ is the waveband.

To improve the computation efficiency, the surface shortwave albedo was calculated using a look-up table (LUT) from the MODIS BRDF/albedo products homepage (http://geography.bu.edu/brdf/). For the "NODATA" value of MCD43B1 product, an annual averaged surface albedo value of 0.22 in the Tibetan plateau is filled as suggested by Yang et al. (2006a,b).

\section{Methodology}

The clear or cloudy sky of each pixel was first flagged using MOD35 and MYD35 data for morning and afternoon atmospheric conditions, separately. Only those determined to be "confident clear with $99 \%$ probability, probably clear with $95 \%$ probability and cloudy" pixel were used for DSSR estimation and validation. For any given solar geometry, surface altitude, ground albedo and AOD, once the atmospheric parameters (total water vapor for clear sky or COT and cloud phase for cloudy sky) are determined, the instantaneous downward shortwave flux at the horizontal surface can be derived from the comprehensive radiative transfer model (MODTRAN, SBDART, 6S, etc.). The LUT for clear and cloudy sky was pre-calculated for various discrete atmospheric and land surface states to improve the computation accuracy and efficiency, and the instantaneous DSSR is linearly interpolated from the LUT based on the input variables. Daily DSSR is calculated by integrating the instantaneous downward flux every $30 \mathrm{~min}$ from sunrise to sunset. To compare the results, the estimated daily DSSR were evaluated against the observations in the TP. A diagram of the DSSR retrieval process is presented in Fig. 2.

\subsection{Creation of LUT}

Because most of the atmospheric radiative transfer model is time consuming, it cannot be run operationally at the pixel level. Generally, the pre-calculated parameters are tabled offline as LUT. The LUT describes the function of direct and diffuse solar irradiance with surface altitude, atmospheric conditions, solar zenith, and land surface albedo. In this study, the downward shortwave fluxes are computed for both clear and cloudy conditions. The atmospheric conditions include visibility, total water vapor for clear sky or cloud phase and COT for cloudy sky. The characteristics of the LUT are listed in Table 3.

We employed the 1-D radiative transfer model, the Santa Barbara DISORT Atmospheric Radiative Transfer (SBDART) code, to create the LUT in this study (Ricchiazzi et al., 1998). SBDART combines the sophisticated discrete ordinate radiative transfer module, low-resolution atmospheric transmission model, and Mie scattering for light scattering by water droplets and ice crystals. A series of sensitivity studies of SBDART were discussed by $\mathrm{Lu}$ et al. (2010). The experiments demonstrate that total downward shortwave flux largely depends on the COT, and the cloud droplet effective radius, the cloud height, and different aerosol types do not significantly affect DSSR under cloudy sky. In our study, the effective radius values were the same as Lu suggested (10 $\mu \mathrm{m}$ for the water cloud droplet and $65 \mu \mathrm{m}$ for the ice cloud droplet). SBDART is run with four streams at a $0.005 \mu \mathrm{m}$ resolution. To simplify the LUT procedure, the ozone and aerosol are considered to be $0.349 \mathrm{~atm} \mathrm{~cm}$ and rural type for the TP.

The defined shortwave wavelength ranging from 0.3 to $3 \mu \mathrm{m}$ corresponds to the default measuring range of the ground-based pyranometers. For cloudy sky, the total water vapor was considered to be $1.418 \mathrm{~g} / \mathrm{cm}^{2}$ as predefined in our standard atmospheric profile because of its small impact on DSSR. For cloudy sky, the cloud cover is 


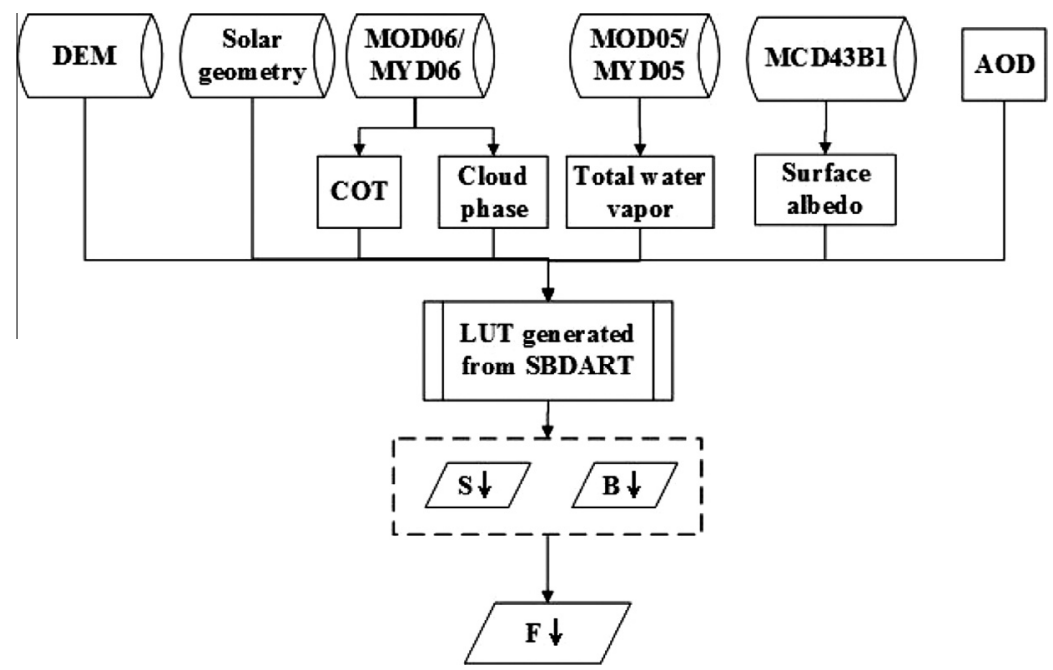

Fig. 2. Flowchart of the algorithm for DSSR estimation.

Table 3

The characteristics of the lookup table.

\begin{tabular}{lll}
\hline Input parameters & Values & Unit \\
\hline Solar zenith angle & $0-89^{\circ}$ at $5^{\circ}$ increments & degree \\
Surface albedo & $0-1$ at 0.1 increments & - \\
Surface altitude & 0,3 and 8 & $\mathrm{~km}$ \\
Visibility & $5,10,20,30$ and 100 & $\mathrm{~km}$ \\
Water vapor & $0.4,0.8,1.4,2.0,2.9,4.1,5.0$ & $\mathrm{~g} / \mathrm{cm}^{2}$ \\
COT & $0,1,3,5,8,12,15,20,30,40,70,100$ & - \\
Cloud phase & Water and ice & - \\
Direct downward flux & & $\mathrm{w} / \mathrm{m}^{2}$ \\
Diffuse downward flux & & $\mathrm{w} / \mathrm{m}^{2}$ \\
\hline
\end{tabular}

assumed to be homogeneous, plane-parallel and temporally stationary during the morning and the afternoon.

\subsection{Downward shortwave flux estimation}

\subsubsection{Direct solar irradiance}

Under isotropic conditions, the direct irradiance on horizontal surface $(B \downarrow)$ can be expressed in terms of the solar irradiance on the top of the atmosphere $\left(B_{0}\right)$, the atmospheric transmittance $(\tau)$, the solar zenith angle $\left(\theta_{i}\right)$ and the solar-earth distance correction factor $\left(I_{\mathrm{CS}}\right)$ :

$B \downarrow=B_{0} \cdot \tau \cdot I_{\mathrm{CS}} \cdot \cos \theta_{i}$

$\tau$ represents the atmospheric transmittance in the shortwave band due to the ozone absorption, molecular scattering, uniformly mixed gas absorption, water vapor absorption, aerosol scattering and absorption, cloud absorption and scattering for cloudy sky.

\subsubsection{Diffuse solar irradiance}

Diffuse irradiance $(S \downarrow)$ at the ground level is a combination of four individual components, corresponding to the irradiance from the molecules $\left(S_{m}\right)$, aerosols $\left(S_{a}\right)$ and clouds $\left(S_{c}\right)$, and the multiple backscattering processes between the surface and the sky $\left(S_{s}\right)$.
$S \downarrow=S_{m}+S_{a}+S_{c}+S_{s}$

Usually, the diffuse irradiance from the aerosols and clouds is a large contribution of the total diffuse irradiance. They are largely dependent on the features of the aerosol particles and the micro-physical parameters of the cloud, such as the cloud particle effective radius and optical thickness. Reflected irradiance generally constitutes only a small proportion of total diffuse irradiance, except for locations surrounded by highly reflective surfaces such as snow cover.

\subsection{Daily integrated DSSR}

The daily DSSR $\left(W_{\mathrm{DSSR}}, \mathrm{MJ} / \mathrm{m}^{2}\right)$ is obtained by integrating the instantaneous shortwave fluxes at 30-min intervals from sunrise to sunset by:

$W_{\mathrm{DSSR}}=\sum_{k=1}^{n+1} \frac{(B \downarrow+S \downarrow)_{\left(t_{k}\right)}+(B \downarrow+S \downarrow)_{\left(t_{k-1}\right)}}{2} \times \Delta t$

$n=\left(t_{\text {sunset }}-t_{\text {sunrise }}\right) / \Delta t+1$

where $n$ is the number of instantaneous DSSR values used to calculate the daily DSSR, $\Delta t$ is the time interval, and $t_{\text {sunset }}$ and $t_{\text {sunrise }}$ are the local time of sunset and sunrise, respectively.

The instantaneous shortwave fluxes at every 30-min intervals were calculated using the LUT interpolation from MODIS atmospheric and land surface data. The input of the instantaneous shortwave fluxes calculation before 10:30 local time was from Terra, and the input of the instantaneous shortwave fluxes calculation after 13:30 local time was from Aqua. The input of the instantaneous shortwave fluxes calculation between 10:30 and 13:30 local time was interpolated from Terra and Aqua images.

\section{Results and discussion}

In this section, the accuracy of our proposed method is evaluated by comparing the estimated DSSR against pyra- 
nometer measurements and global satellite products (GEWEX-SR B 3.0) against the measurements. The temporal resolution of the evaluation is at daily-mean scale.

\subsection{Evaluation with pyranometer measurements}

The validation of daily averaged DSSR was performed by comparing the results with ground measurements of the downwelling shortwave radiation flux on the TP from January to December 2007. The overall validation results are presented in Table 4 in terms of the mean bias error (MBE) between the measurements and the model (calculation-measurement), the root mean square error (RMSE) and the correlation coefficient $\left(R^{2}\right)$ between the estimated and observed values. Fig. 3 shows scatter plots comparing the DSSR observations at $8 \mathrm{CMA}$ sites on the TP with DSSR values derived from MODIS.

The entire estimations exhibit a positive bias (Table 4) and an overestimation trend can be observed at all stations (Fig. 3A). The modeled seasonal DSSR variation agreed with the observed variation (Fig. 3B). The model yields better at Golmud station with MBE of $3.48 \%$ and RMSE of $13.39 \%$, and our estimation yields poorer at Guoluo station with MBE of $18.13 \%$ and RMSE of $31.87 \%$. A possible explanation is that the horizontal surface and dry climate of Golmud station, and a poorer CMA data quality (Table 2) and complex topography of Guoluo station. The averaged DSSR in TP was about $350 \mathrm{~W} / \mathrm{m}^{2}$ in summer and $150 \mathrm{~W} / \mathrm{m}^{2}$ in winter. This was mainly caused by small air masses (nearly half of the sea level) and low aerosol concentrations (almost the lowest) on the TP. The accuracy of our estimated DSSR was better in winter than in summer, which will be discussed in Section 4.2.

The model performance was also evaluated by comparing the solar irradiance retrieval accuracies reported in the literature. Using hourly Meteosat satellite data, MartínezDurbán et al. (2009) reported estimated daily irradiation with a RMSE of $18 \%$ for the north side of the Natural Park of Sierra Nevada, Hueneja (Granada), which has a large topographic diversity (Martínez-Durbán et al., 2009). Yang et al. reported a RMSE of $25 \mathrm{~W} / \mathrm{m}^{2}$ at Lhasa and $20.25 \mathrm{~W} / \mathrm{m}^{2}$ at Golmud using the empirical AngströmPrescott model and sunshine duration as input (Yang et al., 2006a,b). Using MTSAT images, Lu et al. (2011) obtained a RMSE of Tibet of $17.25 \%$ during the winter and $15.64 \%$ during the summer ( $\mathrm{Lu}$ et al., 2011) using hourly MTSAT images and an ANN model. Using the same input and LUT method, Lu also estimated the DSSR with a RMSE of $17.7 \%$ at 96 stations from January to December 2000 in China (Lu et al., 2010) but he did not report the model performance in the TP. Kawai and Kawamura validated the DSSR using GMS-5/VISSR channels with $19.5 \%$ RMS errors (Kawai and Kawamura, 2005). The performance of our model is comparable to the model from the previously discussed literature. These comparisons provide confidence for the applied methodology and demonstrate the feasibility of using pairs of a morning and afternoon MODIS products with a LUT for daily estimates of global solar irradiance.

\subsection{Uncertainty analysis}

The differences in the spatial resolutions between the satellite derived DSSR and the observations may cause errors. The measured data represent the DSSR where the instrument was located. The calculated global radiation fluxes have a $1-\mathrm{km}$ spatial resolution, which may affect the comparison accuracy.

A better accuracy in winter and worse accuracy in summer may be attributed to the frequent variation of the weather caused by the southwest monsoon. The southwest monsoon is a large influence on the TP from May to September and causes a large amount of clouds and rain. There are at most pairs of instantaneous cloud products at approximately 10:30 AM and 1:30 PM each day. Therefore, it is not adequate to capture the variation and physical properties of the cloud. Additionally, compared to the surface observations, the MODIS products largely underestimated cloud frequency over the Tibetan Plateau (up to $50 \%$ ) in summer at seasonal scale (Li et al., 2006), resulting in higher DSSR estimations in our study (Fig. 3B).

COT is the most critical cloud physical parameter for retrieving the DSSR compared to other cloud optical properties. The retrieved COT of MODIS has been validated by many studies (Houborg et al., 2007; Lu et al., 2010). Cirrus clouds cannot always be detected because of the poor cirrus detection capabilities of the MODIS cloud-detection algorithm (http://modis-atmos.gsfc. nasa.gov/validation.html). Additionally, large COT retrieval uncertainties will arise for multiple-layer or horizontally inhomogeneous clouds.

The heterogeneity effects caused by the COT variability and the horizontal transport effect of light moving between cloud columns and the Earth's surface (usually referred to

Table 4

Model evaluation with observations in TP.

\begin{tabular}{|c|c|c|c|c|c|c|c|c|c|c|c|}
\hline \multirow[t]{2}{*}{ Station } & \multirow[t]{2}{*}{$R^{2}$} & \multicolumn{2}{|l|}{ MBE } & \multicolumn{2}{|l|}{ RMSE } & \multirow[t]{2}{*}{ Station } & \multirow[t]{2}{*}{$R^{2}$} & \multicolumn{2}{|l|}{ MBE } & \multicolumn{2}{|l|}{ RMSE } \\
\hline & & $\mathrm{W} / \mathrm{m}^{2}$ & $\%$ & $\mathrm{~W} / \mathrm{m}^{2}$ & $\%$ & & & $\mathrm{~W} / \mathrm{m}^{2}$ & $\%$ & $\mathrm{~W} / \mathrm{m}^{2}$ & $\%$ \\
\hline Gangcha & 0.82 & 21.49 & 10.48 & 45.73 & 22.30 & Guoluo & 0.67 & 34.62 & 18.13 & 60.84 & 31.87 \\
\hline Golmud & 0.90 & 7.78 & 3.48 & 29.97 & 13.39 & Changdu & 0.73 & 33.43 & 16.92 & 52.87 & 26.76 \\
\hline Xining & 0.85 & 33.28 & 18.63 & 49.63 & 27.78 & Ganzi & 0.76 & 19.12 & 8.72 & 43.85 & 20.00 \\
\hline Yushu & 0.73 & 34.78 & 17.58 & 56.11 & 28.37 & Hongyuan & 0.75 & 25.57 & 12.92 & 48.84 & 24.67 \\
\hline
\end{tabular}




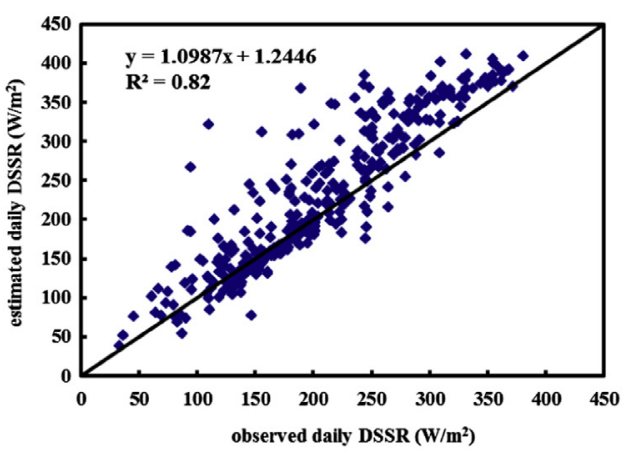

A - Gangcha

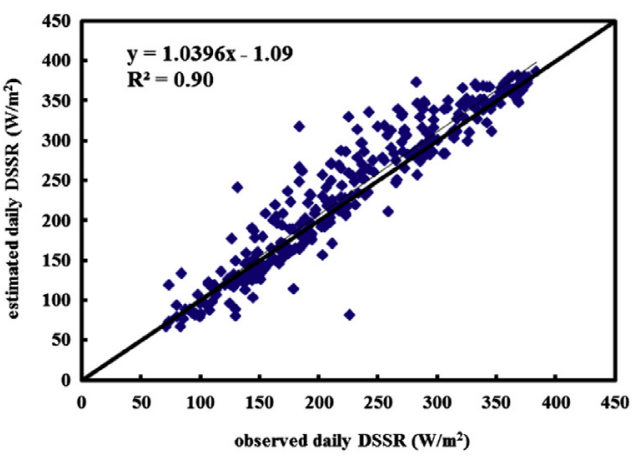

A - Golmud

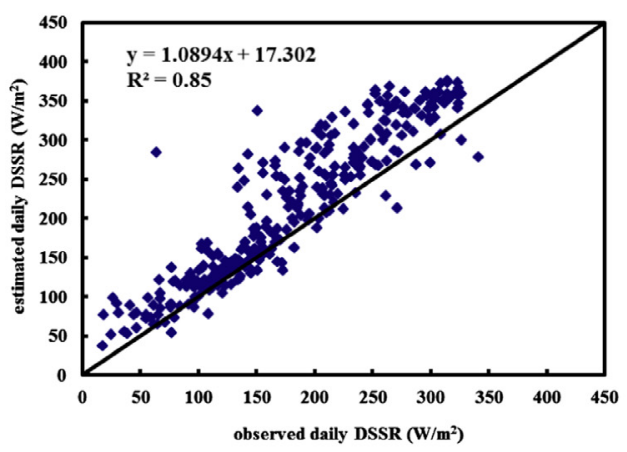

A - Xining

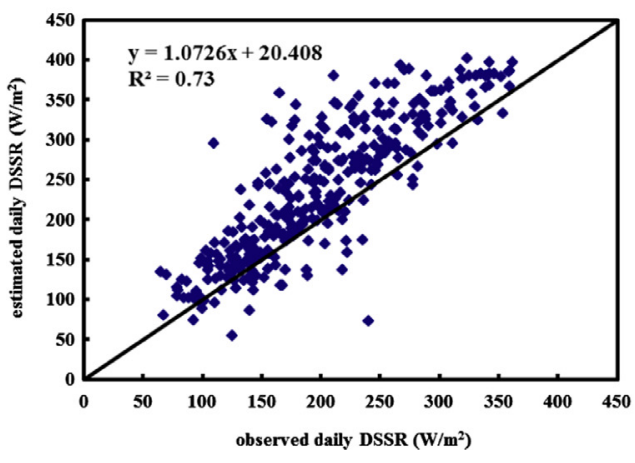

A - Yushu

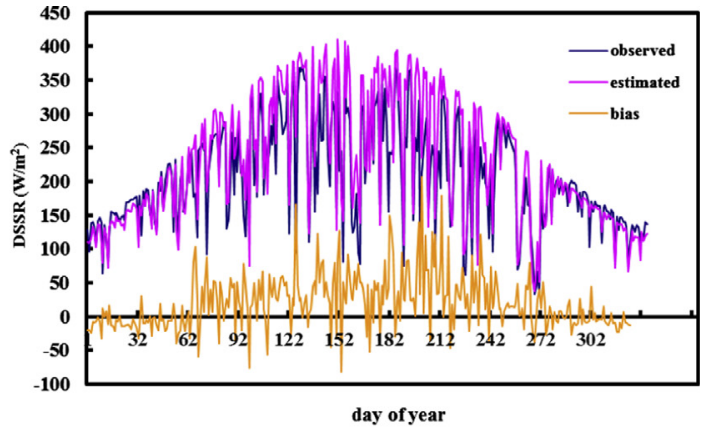

B - Gangcha

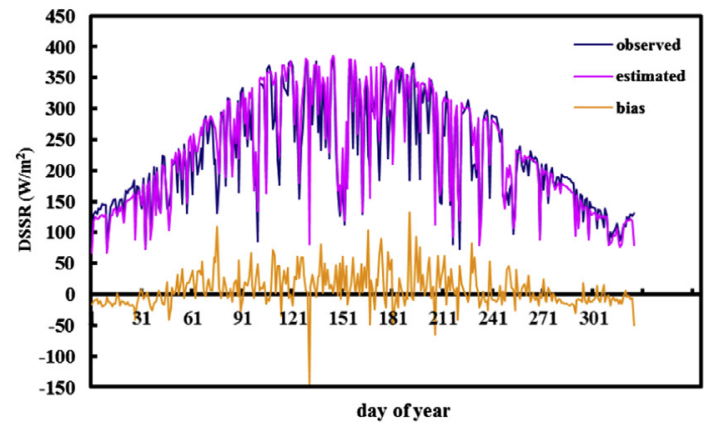

B - Golmud

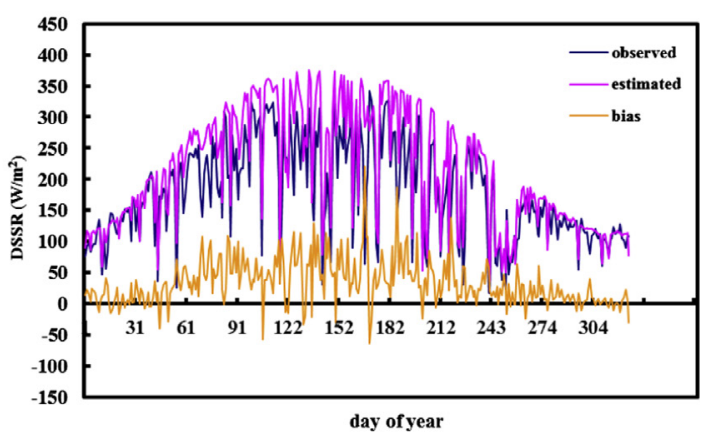

B - Xining

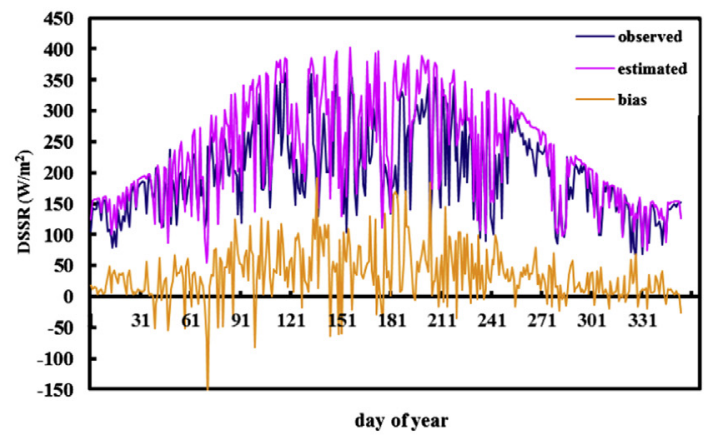

B - Yushu

Fig. 3. Scatter plot between the estimation and the observation (A) and the daily variation and bias of the 8 stations (B).

as the "3D effect") impact the estimation accuracy of the DSSR. The 3D effect is greater at lower solar/viewer elevations and broken cloud fields. However, in our LUT method, the clouds are assumed to be plane-parallel and homogeneous, meaning this simplification will introduce uncertainties. An efficient way to remove the $3 \mathrm{D}$ effect is to use the Monte-Carlo method, and our future research will use a LUT with a 3D model. 


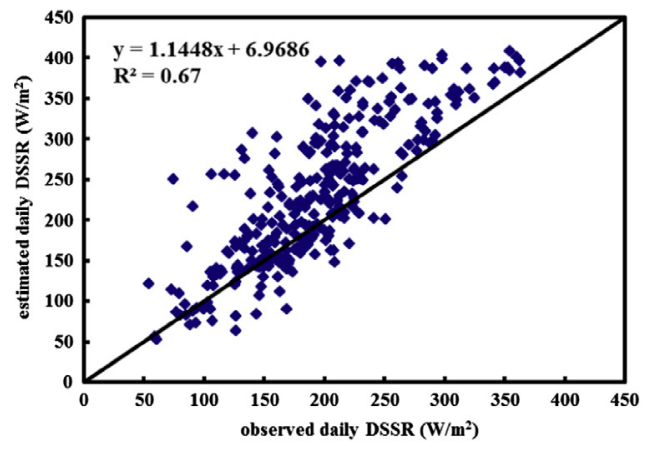

A - Guoluo

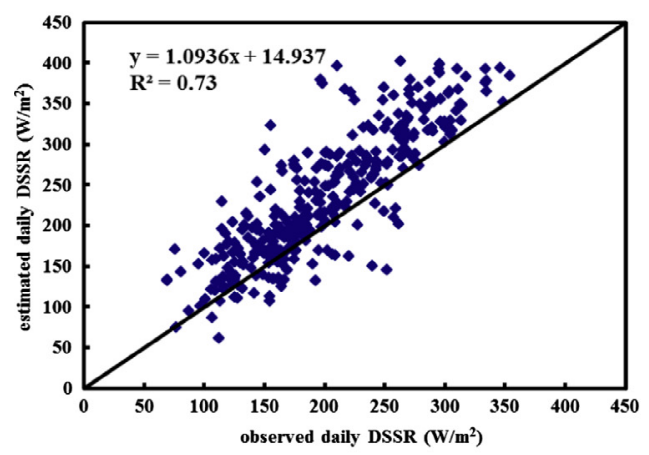

A - Changdu

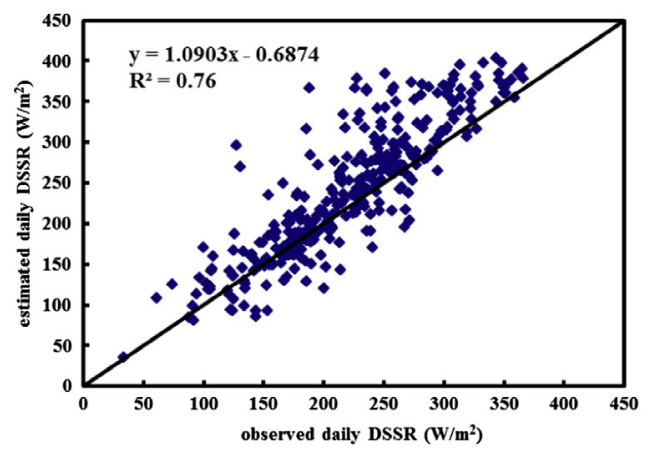

A - Ganzi

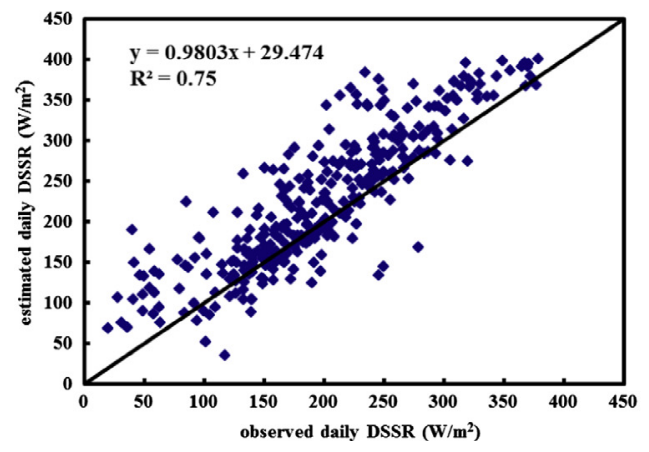

A - Hongyuan

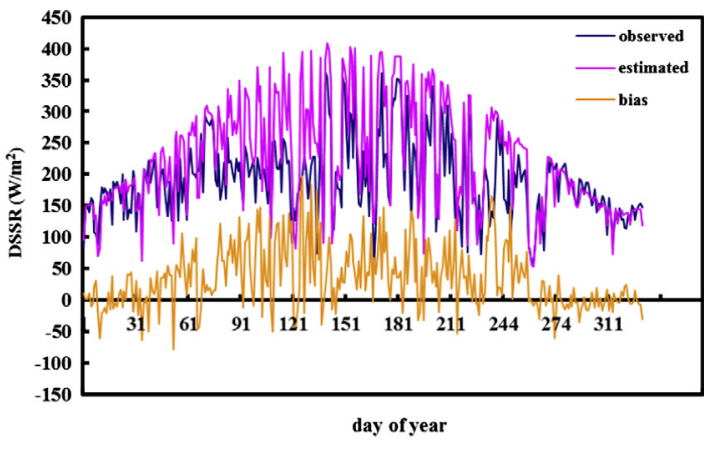

B - Guoluo
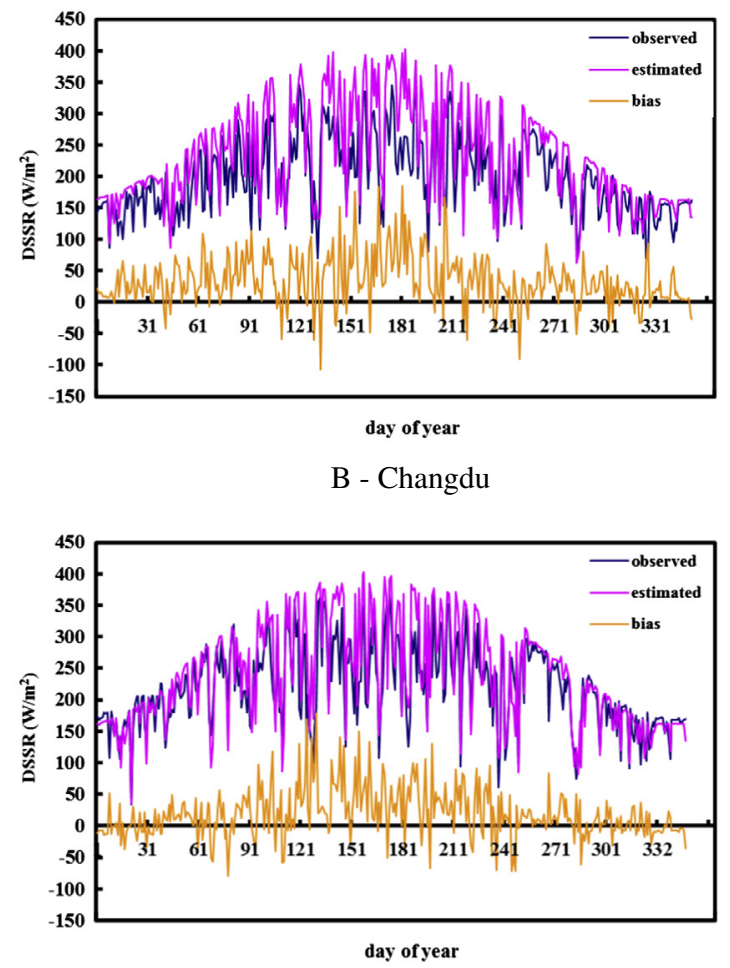

B - Ganzi

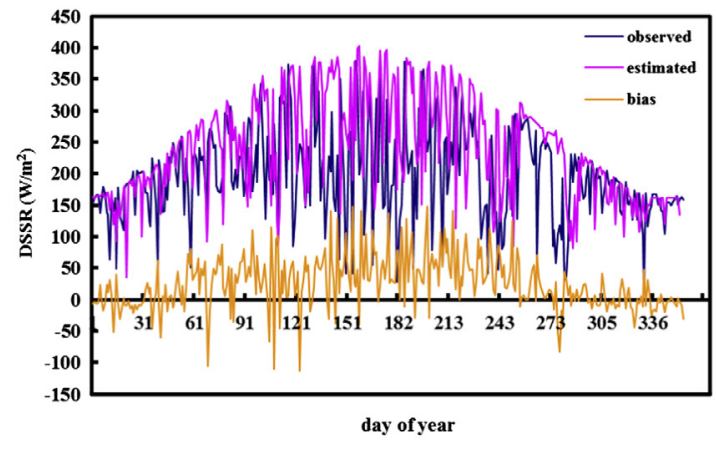

B - Hongyuan

Fig 3. (continued)

\subsection{Comparison with GEWEX-SRB 3.0 data}

The GEWEX-SRB version 3.0 products, with a global resolution of $1^{\circ}$ latitude and longitudinal resolution ranging from $1^{\circ}$ in the tropics and subtropics to $120^{\circ}$ at the poles, were also compared to ground measurements at the 8 stations in the TP. Table 5 provides a statistical comparison of the retrieved and surface-measured DSSR. 
Table 5

Accuracy assessment of GEWEX-SRB with observations in TP.

\begin{tabular}{|c|c|c|c|c|c|c|c|c|c|c|c|}
\hline \multirow[t]{2}{*}{ Station } & \multirow[t]{2}{*}{$R^{2}$} & \multicolumn{2}{|l|}{ MBE } & \multicolumn{2}{|l|}{ RMSE } & \multirow[t]{2}{*}{ Station } & \multirow[t]{2}{*}{$R^{2}$} & \multicolumn{2}{|l|}{ MBE } & \multicolumn{2}{|l|}{ RMSE } \\
\hline & & $\mathrm{W} / \mathrm{m}^{2}$ & $\%$ & $\mathrm{~W} / \mathrm{m}^{2}$ & $\%$ & & & $\mathrm{~W} / \mathrm{m}^{2}$ & $\%$ & $\mathrm{~W} / \mathrm{m}^{2}$ & $\%$ \\
\hline Gangcha & 0.84 & 20.08 & 9.79 & 37.98 & 18.52 & Guoluo & 0.68 & 25.52 & 13.37 & 46.23 & 24.21 \\
\hline Xining & 0.81 & 53.37 & 29.87 & 63.61 & 35.60 & Ganzi & 0.66 & 14.97 & 6.83 & 42.74 & 19.49 \\
\hline Yushu & 0.81 & 32.83 & 16.60 & 45.11 & 22.81 & Hongyuan & 0.71 & 10.45 & 5.28 & 41.22 & 20.82 \\
\hline
\end{tabular}

Table 6

Accuracy assessment of our estimation up-scaled to $1^{\circ}$ resolution.

\begin{tabular}{|c|c|c|c|c|c|c|c|c|c|c|c|}
\hline \multirow[t]{2}{*}{ Station } & \multirow[t]{2}{*}{$R^{2}$} & \multicolumn{2}{|l|}{ MBE } & \multicolumn{2}{|l|}{ RMSE } & \multirow[t]{2}{*}{ Station } & \multirow[t]{2}{*}{$R^{2}$} & \multicolumn{2}{|l|}{ MBE } & \multicolumn{2}{|c|}{ RMSE } \\
\hline & & $\mathrm{W} / \mathrm{m}^{2}$ & $\%$ & $\mathrm{~W} / \mathrm{m}^{2}$ & $\%$ & & & $\mathrm{~W} / \mathrm{m}^{2}$ & $\%$ & $\mathrm{~W} / \mathrm{m}^{2}$ & $\%$ \\
\hline Gangcha & 0.87 & 7.38 & 3.74 & 36.42 & 18.46 & Guoluo & 0.70 & 17.61 & 9.71 & 52.31 & 28.84 \\
\hline Xining & 0.89 & 27.21 & 15.72 & 43.52 & 25.14 & Ganzi & 0.76 & 0.95 & 0.44 & 37.27 & 17.31 \\
\hline Yushu & 0.74 & 20.31 & 10.27 & 46.25 & 23.39 & Hongyuan & 0.77 & 7.17 & 3.68 & 40.53 & 20.80 \\
\hline
\end{tabular}

Our estimation with $1 \mathrm{~km}$ resolution was up-scaled to $1^{\circ}$ resolution in order to comparable with the GEWEXSRB product and the results are listed in Table 6.

The GEWEX-SRB data overestimated DSSR and yielded a poor data quality in TP. The up-scaled DSSR derived from our LUT based algorithm with a $1 \mathrm{~km}$ resolution has a lower MBE and RMSE than the GEWEXSRB product except Guoluo (RMSE of GEWEX-SRB is $24.21 \%$, and RMSE of our estimation is $28.84 \%$ ). The validation of GEWEX-SRB also had a poorer data quality at Changdu and Xining than the other stations with larger RMS errors of $28.19 \%$ and $35.60 \%$, respectively (Table 5). The largest difference of the comparison was at Xining station, with a RMSE of $35.60 \%$ and $25.14 \%$, respectively. Considering the multi-source input data of GEWEXSRB products (the cloud parameter input data were from ISCCP-DX data that were collected from geostationary images, and the temperature and total water vapor data were from GSFC and GEOS-4), the result of our proposed model is very promising.

\section{Conclusions}

This paper describes and evaluates a LUT algorithm based all-sky DSSR retrieval, which combines the satellite images and a sophisticated 1D radiative transfer model. The accuracy of the retrieval has been quantified for all sky conditions at 8 stations in the Tibetan Plateau using one year pyranometer measurements. The best results are achieved during the winter and the worst results are achieved during the summer. Our proposed model improved the DSSR retrieval compared to GEWEX-SRB version 3.0 with a $1^{\circ}$ spatial resolution with a RMSE reduced by approximately $1-10 \%$. The use of MODIS data from two instantaneous images during the day in combination with a LUT algorithm scheme made daily estimates of DSSR feasible from sunrise until sunset. Our proposed scheme can provide significantly improved daily DSSR estimates in regions with sparse meteorological observations and complex terrain. The model is theoretically versatile and is not climate dependent, and thus, it can be used to predict the daily DSSR at any place if the AOD or visibility data can be easily derived.

The uncertainties of the model may be caused by assuming the clouds to be homogeneous and the derived moderate temporal cloud physical properties from MODIS. The uncertainty of the MODIS cloud retrievals may also result in inadequate descriptions of the atmospheric state for overcast conditions. For clear sky, the main variables driving the insolation levels on the surfaces are the solar elevation and the surface elevation. For cloudy conditions, the clouds may cause a high spatial-temporal variability on the incident solar irradiance.

The benefits of using MODIS are related to its good cloud characterization and retrieval capabilities at unprecedented spatial resolutions that permit the integrated use of accurate radiative transfer schemes. Its disadvantage is the temporal resolution. Future work will focus on a synergistic combination of polar orbiting, such as MODIS and FY3 , with the capability of deriving land/clear-sky atmospheric conditions and geostationary satellites, such as GOES, FY-2, and GMS, which are potentially useful to capture the daily cycle of cloud variation.

\section{Acknowledgments}

This work was supported in part by the Special Fund from Chinese Academy of Sciences (KZZD-EW-TZ-18), in part by the Chinese Natural Science Fund Project (41201352 and 41371360), the Open Foundation of the State Key Laboratory of Loess and Quaternary Geology, Institute of Earth Environment, CAS (SKLLQG1427), and the State Key Laboratory of Resources and Environmental Information System, Institute of Geographical Sciences and Natural Resources Research, CAS. 
The solar radiation measurements were provided by the Climatic Data Center, National Meteorological Information Center, China Meteorological Administration. MODIS atmospheric products were provided by NASA, USA, from their Web site at http://ladsweb.nascom.nasa.gov/data/.

\section{References}

Ångström, A., 1924. Solar and terrestrial radiation. Report to the international commission for solar research on actinometric investigations of solar and atmospheric radiation. Quart. J. Roy. Meteorol. Soc. 50, 121-125.

Behrang, M.A., Assareh, E., Ghanbarzadeh, A., Noghrehabadi, A.R., 2010. The potential of different artificial neural network (ANN) techniques in daily global solar radiation modeling based on meteorological data. Sol. Energy 84, 1468-1480.

Dubayah, R., Loechel, S., 1997. Modeling topographic solar radiation using GOES data. J. Appl. Meteorol. 36, 141-154.

Ertekin, C., Evrendilek, F., 2007. Spatio-temporal modeling of global solar radiation dynamics as a function of sunshine duration for Turkey. Agric. For. Meteorol. 145, 36-47.

Gupta, S.K., Ritchey, N.A., Wilber, A.C., Whitlock, C.H., Gibson, G.G., Stackhouse, P.W., 1999. A climatology of surface radiation budget derived from satellite data. J. Clim. 12, 2691-2710.

Houborg, R., Soegaard, H., Emmerich, W., Moran, S., 2007. Inferences of all-sky solar irradiance using Terra and Aqua MODIS satellite data. Int. J. Remote Sens. 28, 4509-4535.

Journee, M., Bertrand, C., 2010. Improving the spatio-temporal distribution of surface solar radiation data by merging ground and satellite measurements. Remote Sens. Environ. 114, 2692-2704.

Kawai, Y., Kawamura, H., 2005. Validation and improvement of satellitederived surface solar radiation over the Northwestern Pacific Ocean. J. Oceanogr. 61, 79-89.

Kim, H., Liang, S., 2010. Development of a hybrid method for estimating land surface shortwave net radiation from MODIS data. Remote Sens. Environ. 114, 2393-2402.

Li, Y., Liu, X., Chen, B., 2006. Cloud type climatology over the Tibetan Plateau: a comparison of ISCCP and MODIS/TERRA measurements with surface observations. Geophys. Res. Lett. 33, L17716.

Lu, N., Liu, R., Liu, J., Liang, S., 2010. An algorithm for estimating downward shortwave radiation from GMS 5 visible imagery and its evaluation over China. J. Geophys. Res.-Atmos. 115, D18102.

Lu, N., Qin, J., Yang, K., Sun, J., 2011. A simple and efficient algorithm to estimate daily global solar radiation from geostationary satellite data. Energy 36, 3179-3188.

Martínez-Durbán, M., Zarzalejo, L.F., Bosch, J.L., Rosiek, S., Polo, J., Batlles, F.J., 2009. Estimation of global daily irradiation in complex topography zones using digital elevation models and meteosat images: comparison of the results. Energy Convers. Manage. 50, 2233-2238.

Meza, F., Varas, E., 2000. Estimation of mean monthly solar global radiation as a function of temperature. Agric. For. Meteorol. 100, 231-241.
Perez, R., Ineichen, P., Moore, K., Kmiecik, M., Chain, C., George, R., Vignola, F., 2002. A new operational model for satellite-derived irradiances: description and validation. Sol. Energy 73, 307-317.

Qin, J., Chen, Z., Yang, K., Liang, S., Tang, W., 2011. Estimation of monthly-mean daily global solar radiation based on MODIS and TRMM products. Appl. Energy 88, 2480-2489.

Ricchiazzi, P., Yang, S., Gautier, C., Sowle, D., 1998. SBDART: a research and teaching software tool for plane-parallel radiative transfer in the earth's atmosphere. Bull. Am. Meteorol. Soc. 79, 2101-2114.

Rigollier, C., Lefèvre, M., Wald, L., 2004. The method Heliosat-2 for deriving shortwave solar radiation from satellite images. Sol. Energy 77, 159-169.

Rivington, M., Matthews, K.B., Bellocchi, G., Buchan, K., 2006. Evaluating uncertainty introduced to process-based simulation model estimates by alternative sources of meteorological data. Agric. Syst. 88, 451-471.

Ryu, Y., Kang, S., Moon, S.K., Kim, J., 2008. Evaluation of land surface radiation balance derived from moderate resolution imaging spectroradiometer (MODIS) over complex terrain and heterogeneous landscape on clear sky days. Agric. For. Meteorol. 148, 1538-1552.

Shi, G., Hayasaka, T., Ohmura, A., Chen, Z., Wang, B., Zhao, J., Che, H., Xu, L., 2008. Data quality assessment and the long-term trend of ground solar radiation in China. J. Appl. Meteorol. Climatol. 47, 1006-1016.

Tang, W.J., Yang, K., He, J., Qin, J., 2010. Quality control and estimation of global solar radiation in China. Sol. Energy 84, 466-475.

Wild, M., Ohmura, A., Gilgen, H., Roeckner, E., 1995. Validation of general circulation model radiative fluxes using surface observations. J. Clim. 8, 1309-1324.

Xue, Y., He, X., Xu, H., Guang, J., Guo, J., Mei, L., 2014. China Collection 2.0: the aerosol optical depth dataset from the synergetic retrieval of aerosol properties algorithm. Atmos. Environ. 95, 45-58.

Yang, K., Koike, T., 2002. Estimating surface solar radiation from upperair humidity. Sol. Energy 72, 177-186.

Yang, K., Koike, T., Stackhouse, P., Mikovitz, C., Cox, S.J., 2006a. An assessment of satellite surface radiation products for highlands with Tibet instrumental data. Geophys. Res. Lett. 33, L22403.

Yang, K., Koike, T., Ye, B.S., 2006b. Improving estimation of hourly, daily, and monthly solar radiation by importing global data sets. Agric. For. Meteorol. 137, 43-55.

Yang, K., Pinker, R.T., Ma, Y., Koike, T., Wonsick, M.M., Cox, S.J., Zhang, Y., Stackhouse, P., 2008. Evaluation of satellite estimates of downward shortwave radiation over the Tibetan Plateau. J. Geophys. Res.-Atmos. 113, D17204.

Yang, K., He, J., Tang, W.J., Qin, J., Cheng, C., 2010. On downward shortwave and longwave radiations over high altitude regions: observation and modeling in the Tibetan Plateau. Agric. For. Meteorol. 150, 38-46.

Zhang, X., Zhang, Y., Zhoub, Y., 2000. Measuring and modelling photosynthetically active radiation in Tibet Plateau during AprilOctober. Agric. For. Meteorol. 102, 207-212. 